\title{
The Research on the Types and Functions of Ethical Statute of College Students' Mental Health Education
}

\author{
Xiaofang Chen ${ }^{1}$, Jianqing $\mathrm{Ma}^{2}$ \\ ${ }^{1}$ Marxist college, Zhejiang University, Zhejiang province, 310018, China; \\ ${ }^{2}$ Marxist college, Zhejiang University, Zhejiang province, 310018, China.
}

Keywords: Mental health education of college students; ethics; type; function

\begin{abstract}
The ethical statute of mental health of college students can be divided into two types of ethical demands: "internal" and "external", in which the internal and external demands are mainly embodied as "relationship ethics" and "practical ethics". In the ecological horizon of the ethical construction of college students' mental health education, this paper expounds the role and significance of ethics in the work of mental health education of college students, focusing on the functions of cognition orientation, adjusting feedback, reforming and promoting and leading the increment of value.
\end{abstract}

\section{Types of Ethical Statutes of College Students' Mental Health Education}

The work of mental health education of college students has its own distinct ethical spirit, and its ethical demands are derived from both endogenous and external demands, that is, the demands of the moral development of college students' mental health educators and the demands of society, stakeholders on the mental health educators of college students. The ethical appeal is often related to the "fair" or "good", that is, the pursuit of the "good". On the one hand, the ethical appeal is the subjective requirement of the subject; on the other hand, it is also a vital requirement of the ethics itself.

\subsection{The endogenous ethical statute}

The mental health education of college students is a self-improvement system, a special form of ethical community, with its own internal development of rules and system structure. The internal ethical basis and premise of college students' mental health education is to deal with the relationship between the subject, including, individuals and organizations, individuals and things, individuals and university environment, and individuals and themselves, to grasp and deal with various relations in the field of mental health education in colleges and universities, which embodies the norms and guidance of "how to" or "how should" do in each kind of relationship ${ }^{[1]}$. Through the cognition and grasp of a series of relationships, to achieve a certain degree of coordination to promote the smooth operation of college students' mental health undertakings. The cognition and grasp of a series of relationships help to achieve a certain degree of coordination, which promotes the smooth operation of college students' mental health undertakings. This is the inner appeal type of the ethical standard construction of college students' mental health education work.

\subsection{The exogenous ethical statute}

The ethical norm system of college students' mental health education is a kind of "sub-system" form, it is not only in terms of the organizational form, but also from the perspective of practical form, relative to the whole social system. It is bound to pass through the practical path of "seeking from outside" to contact with the outside world. McKinley once argued that "The real world of man is not the world of giving, but the world created with the participation of man in his own activities.” Returning to the process of ethical standard construction of college students' mental health education, educators should not only meet their own development needs, but also combine the individual development plan of the main body and the expectation and requirement of the whole country and society to the mental health education work, to achieve moral self-interest and emotional altruism ${ }^{[2]}$. The practical activities of mental health education not only create the activities between people, but also create the human life world and the object world, and create the demands of external ethics construction with certain practice ethic forms. 


\subsection{The interactive ethical statute}

Habermas, through the deconstruction and rewriting of "reality", has been closely connected with the life world, constructing a huge communicative behavior theory and solving all kinds of communication problems in the real society. From the point of view of a harmonious and benign ecology, the norm construction of college students' mental health education has the tradition and benign mechanism of "internal and external interaction" and "mutual communication" on ethical demands. Through mutual consultation and cooperation, it expresses "consensus" in the form of treaties, achieving the goal of understanding during the teaching process of psychological counseling, psychological interviews, and group guidance. In the process of constantly dealing with "relationship ethics" and pursuing "practical ethics", the harmonious ethical structure of communication practice is formed through running-in and interaction, which has a positive and beneficial influence on the construction of ethical norms of college students' mental health.

\section{Functions of Ethical Statute of College Students’ Mental Health Education}

The ethical standard construction of college students' mental health education is a kind of ethics construction activity in a special field. It provides the possibility to improve the service quality of college students' mental health education, and it also plays an extremely important role in influencing the students' mental health education. As a basic form of human spiritual life, ethics is the creation of human beings, and the reason for its existence lies in the value provided by ethical function. Kant showed immeasurable praise and love for ethical values which was called "the starry sky above my heart and the moral law in my heart" by him. The significance of professional ethics in the norm construction of college students' mental health education is that it is helpful to protect the rights and welfare of the parties, to improve the effect of psychological counseling, and to establish a good social image of mental health education workers. It is beneficial to the permanent development of mental health education, referring to the functions of cognitive guidance, feedback regulation, reform and promotion, and leading value added, etc.

\subsection{The function of cognitive guidance}

Ethics plays a cognitive role in the construction of mental health education for college students. It can be understood from two aspects: on the one hand, ethics itself has a special way of cognition and cognitive ability in the world of human cognition ${ }^{[3]}$. In the process of mental health education for college students, ethics can reflect the relationship between the subjects of mental health education and the subjects to be educated, the management departments and organizations, the society and the stakeholders in colleges and universities, and help the subjects of mental health education to establish the ethical value goals and normative system of mental health. On the other hand, ethics has the function of pointing, guiding and standardizing people's habits, activities or behavior patterns. Ethics itself contains the proper and reasonable normative consciousness and action instruction, which affects people's cognition and behavior, and its main characteristics include necessity and legitimacy. Ethics is the moral behavior choice and evaluation of college students' mental health educators in the corresponding teaching process, and sets up the criterion and standard of judging good and evil in the process of education and teaching, to form a unified, clear evaluation standard of good and evil in the environment of mental health education in colleges and universities, obtain invisible guiding force and binding force, and consciously make the subjects of mental health education maintain, construct and adjust their own behavior rules.

\subsection{The function of feedback regulation}

To some extent, regulating function is the inevitable result of exerting ethics-oriented function. On the one hand, because of the feature of ethic, the ethical norm of mental health educator is to coordinate the common needs among educators and students, educators and educators, educators and schools, and educators and the society. However, sometimes in the process of practice, the mentioned needs may be consistent as well as inconsistent, or even cause the opposite effect ${ }^{[4]}$. Through the mutual regulation and coordination of ethics, the work of mental health education in university can be kept in order to maintain the normal operation of mental health education for college students. On the other hand, mental health education workers and students, other jobs and society have a certain degree of interaction at any time, individuals and individuals, groups 
and individuals will inevitably have certain social relations and interests. In the specific field of mental health education practice, the following approach is recommended to finally seek or reach a consensus. Conducting a series of practical activities, such as psychological counseling, psychological interviews and group counseling, achieving the establishment of ethical evaluation standards for related issues, and combining internal regulation and external regulation so that the multi-party understanding is realized on the basis of the establishment of ethical evaluation.

\subsection{The function of reform and promotion}

In the course of the construction of mental health education in China, its ethical basis and atmosphere are the essential forces to promote the reform of mental health system. The rationality of ethics and morality in the work of mental health education is a basic criterion of value evaluation. Its core function is to require the psychological organization and the corresponding managers to follow the combination of their teaching efficiency and the moral rationality of the teaching behavior in the mental health activities. Nowadays, many people only care about the most basic logical problems, but don't care about the ultimate purpose of human beings and what can maintain a just social order ${ }^{[5]}$. Of course, it is still a problem that needs to be solved. Good ethics is a kind of good economics. Only when a policy is conducive to society can it be advantageous to enterprises and people. College students' mental health education in our country has been developing for more than 30 years. On the premise of the universality of value, we also realize the importance of the construction of ethical norms of mental health education, and actively think about the guidance of the construction of ethical spirit. The reform and promotion of the whole mental health education is the direction that needs further thinking and exploration in the future.

\subsection{The function of leading and value-added role}

For mental health educators, real psychological guidance requires both professional characteristics and personality charm, which affects the development of teacher-student and management teaching. It also has a kind of leadership explosiveness, which help students get out of their own difficult situation and meet the new meaning life. There are generally many incentives, which can be summarized from three aspects according to the survey results. One is external stimulus factors (such as money and wealth), the other is individual growth and job autonomy, and the third is, to sum up, the strength based on faith and ethics ${ }^{[6]}$. Compared with the former two, people's behavior is often intensely influenced by psychological factors, and the motivation effect of the last one is more profound and lasting, thus achieving and obtaining the positive teaching effect through ethics. Ethics not only can dominate and promote the organization members to cultivate the emotion of "justice, kindness and beauty", but also can stimulate the occurrence of ethical behavior of mental health educators. It can give full play to the incentive function of ethics in the whole process of mental health education, so that psychological educators can be encouraged to consciously do the behaviors needed and expected by ethics, achieving the goal of mental health education in colleges and universities, based on which the systematic requirements of the "relationship mode" of the whole educational management set by ethical management are realized, the expected results are obtained, and the goals of mental health education in colleges and universities are achieved. In the whole development of mental health education, ethical spirit realizes the emotional cohesion, moral education and moral appreciation, and realizes the function of leading and adding value from form to essence.

\section{Conclusion}

The famous educator Husen once said, "as a practical field, the true essence of education lies in its locality and nationality. After all, education is formed by the cultural and historical traditions of the specific country it serves." Universities are not completely independent organizations existed in the social ecology. With the development of international higher education, the scale of talent training in Chinese universities has leapt to the first in the world, and in the period of the establishment and improvement of the market economy system, The background of popularization and marketization will inevitably affect the development of teachers and students in universities. In this process, we have to face the new ethical dilemma of education. Based on the discussion of the types and functions of the ethical statute of mental health education of college students, this 
paper further clarifies the important role of ethics in the construction of professional norms of mental health education. The purpose is not only to ensure the rights and interests of the parties concerned, but also to ensure the well-being of the parties concerned. Moreover, it is helpful to improve the effect of mental health education of college students and urge its professional and permanent development.

\section{References}

[1]. Xiaoqing Sun and Daoyang Wang, Progress of Mental Health Education in American Schools. China Health Care Management, 2008. 25(11): p. 771-774.

[2]. Gang Feng, Insist on the cultivation of moral Education, pay attention to improving the quality and promote the Innovation and Development of College studentsundefined Mental Health Education. Research on ideological and political Education, 2014.30(1): p. 1-4.

[3]. Sonne, J.L., Multiple relationships: Does the new ethics code answer the right questions? Prof Psychol Res Pr, 1994. 25(4): p. 336-343.

[4]. Pope, K.S., B.G. Tabachnick and P. Keith-Spiegel, Ethics of practice. The beliefs and behaviors of psychologists as therapists. Am Psychol, 1987. 42(11): p. 993-1006.

[5]. Guangming Liu, It is urgent to combine economics with ethics. Corporate culture, 2002(6): p. 17-20.

[6]. Jingyuan Xiang, A probe into the incentive Mechanism of College Teachers. Journal of Chengdu Normal University, 2002.18(5): p. 19-21. 